Published in final edited form as:

Epidemiology. 2007 November ; 18(6): 747-757.

\title{
Perceived Racial Discrimination and Risk of Uterine Leiomyomata
}

\author{
Lauren A. Wise ${ }^{\star}$, Julie R. Palmer ${ }^{\star}$, Yvette C. Cozier ${ }^{\star}$, Matthew O. Hunt ${ }^{\dagger}$, Elizabeth A. \\ Stewart ${ }^{\ddagger}$, and Lynn Rosenberg \\ *Slone Epidemiology Center, Boston University, Brigham and Women's Hospital, Harvard Medical School, \\ Boston, Massachusetts.
}

†Department of Sociology, Northeastern University, Brigham and Women's Hospital, Harvard Medical School, Boston, Massachusetts.

$\ddagger$ Center for Uterine Fibroids, Department of Obstetrics, Gynecology, and Reproductive Biology, Brigham and Women's Hospital, Harvard Medical School, Boston, Massachusetts.

\begin{abstract}
Background-The incidence of uterine leiomyomata (fibroids, myomas) is 2-3 times higher in black women than white women. Black women also report higher levels of racial discrimination. We evaluated the hypothesis that greater exposure to racism increases myoma risk in black women.

Methods-Data were derived from the Black Women's Health Study, a prospective cohort study of US black women age 21-69 years in 1995. In 1997, women reported on "everyday" and "lifetime" experiences of racism. From 1997 through 2003, we followed 22,002 premenopausal women to assess the association between self-reported racism and risk of myomas. Incidence rate ratios (IRRs) and 95\% confidence intervals (CIs) were estimated from Cox regression models.
\end{abstract}

Results-During 107,127 person-years of follow-up, 3440 new cases of uterine myomas confirmed by ultrasound $(n=2774)$ or surgery $(n=666)$ were reported. All IRRs for "lifetime" and "everyday" experiences of racism were above 1.0. Using a summary variable that averaged the responses from 5 "everyday" racism items, multivariable IRRs comparing quartiles 2,3 , and 4 to quintile 1 (lowest) were 1.16 (95\% CI = 1.04-1.29), $1.19(1.06-1.32)$, and 1.27 (1.14-1.43), respectively. Multivariable IRRs comparing women who reported 1, 2, or 3 lifetime occurrences of major discrimination (ie, job, housing, or police) relative to those who reported none were 1.04 (0.96-1.13), 1.17 (1.07-1.28), and 1.24 (1.10-1.39), respectively. Results did not vary according to case definition (ultrasound vs. surgery) or health care utilization. Associations were weaker among foreign-born women and among women with higher coping skills.

Conclusions-Perceived racism was associated with an increased risk of uterine myomas in USborn black women.

Uterine leiomyomata (fibroids, myomas) are benign neoplasms arising from smooth muscle cells of the uterus. Myomas are clinically recognized in about $30 \%$ of reproductive-aged women $^{1-3}$ and are the primary indication for hysterectomy among US women, 4,5 with annual healthcare costs exceeding 2.1 billion dollars. ${ }^{6}$ Relative to white women, black women have 2-3 times the incidence of myomas, ${ }^{4,7-9}$ earlier ages at clinical presentation, ${ }^{7,9}$ and more numerous and symptomatic tumors at the time of diagnosis. $7,9,10$ Population differences in the prevalence of known risk factors or screening patterns do not satisfactorily explain the racial disparity. $7,10-12$

Correspondence: Lauren A. Wise, Slone Epidemiology Center, 1010 Commonwealth Avenue, Boston, MA, 02215. E-mail: lwise@slone.bu.edu.. 
In recent years, there has been growing interest in possible connections between self-reported racism and health. Racism can affect health status by limiting access to societal resources, ${ }^{13}$ delaying help-seeking among ill individuals, ${ }^{14}$ affecting the quality of medical diagnosis and treatment, ${ }^{15}$ and elevating stress. ${ }^{16-19}$ Although consistent associations have been found between self-reported racism and poor mental health and health-related behaviors, results have been mixed for physical health outcomes such as low birth weight, increased blood pressure, and cardiovascular disease. ${ }^{20}$ Whether exposure to racism is a determinant of myoma risk has not been explored previously.

Myoma pathogenesis is thought to depend on estrogens and progesterone 21,22 and their interaction with growth factors, cytokines, and extracellular matrix components, including collagen and matrix metalloproteinases. ${ }^{23}$ Racism, which can elevate stress levels, ${ }^{16-19}$ is experienced more frequently by black women than white women. 24 "Allostatic load," a measure of cumulative exposure to stress over the lifecourse, 25,26 is also higher in black women than white women. ${ }^{27}$ Several stress biomarkers used to quantify allostatic load, including cortisol, norepinephrine, epinephrine, and elevated blood pressure, ${ }^{26-28}$ have been linked to myoma risk. ${ }^{29-34}$ An effect of racism on myoma risk via allostatic load is biologically plausible because stress hormones activate the hypothalamic-pituitary-adrenal axis leading to enhanced glucocorticoid (eg, cortisol) secretion, inhibited gonadotropin secretion, altered synthesis of ovarian hormones, 35,36 and disrupted menstrual cyclicity. ${ }^{37}$ Stress-related increases in the secretion of progesterone are well-documented in animal ${ }^{38-42}$ and human ${ }^{43-46}$ studies, and higher endogenous concentrations of progesterone can increase myoma risk. ${ }^{22}$ Moreover, various growth factors, cytokines, and matrix metalloproteinases involved in myoma growth can be upregulated by stress hormones. ${ }^{47,48}$ Finally, myomaslike hypertension - are a disease of smooth muscle cells, and both conditions could share a pathogenic mechanism. ${ }^{32-34}$ Hemo-dynamic stress due to elevated blood pressure may cause arterial smooth muscle injury leading to endothelial dysfunction, increased permeability, and fibrous plaque formation. 33,49 Uterine smooth muscle cells may suffer the same type of injury, resulting in myoma formation.

Using data from a large US prospective cohort study of black women, we evaluated the hypothesis that perceived racism increases the risk of uterine myomas. Differences in the association were explored according to factors such as nativity status and coping skills, which have been shown to modify the relation of self-reported racism with other health outcomes. 50-55

\section{METHODS}

\section{Study Population}

The Black Women's Health Study is a prospective cohort study that was established in 1995. Approximately 59,000 black women in the United States age 21-69 years, were enrolled through self-administered questionnaires mailed primarily to subscribers of Essence, a magazine targeted to black women. ${ }^{56}$ Study respondents represent various geographic regions of the United States, with the majority residing in California, New York, Illinois, Michigan, Georgia, and New Jersey. Questionnaires are mailed every 2 years to update exposures and identify new illnesses. The baseline (1995) questionnaire elicited information on demographic and lifestyle factors, health care utilization, and medical conditions. In 1997, women were asked about their race, ethnicity, and country of birth. Those who did not selfidentify as "black" were dropped from the cohort. Six percent of women were foreign-born (54\% Caribbean, 7\% Africa, 39\% Europe/South America/North America/Asia/Other) and less than 2\% reported Hispanic ethnicity. Over $80 \%$ of the original cohort completed a questionnaire in each followup cycle through 2003. The institutional review boards of Boston University Medical Center and Howard University Cancer Center approved the study protocol. 


\section{Assessment of Exposure and Other Covariates}

On the 1997 questionnaire, women were asked 8 questions about experiences of racial discrimination, adapted from those developed by Williams and colleagues. ${ }^{17}$ Three questions asked about their experience (yes vs. no) of being "treated unfairly due to your race" in 3 settings: on the job, in housing, and by the police. We refer to these as "lifetime" experiences of racism. Five questions asked about the frequency of exposure to discrimination in daily life, phrased as follows: "In your day-to-day life, how often have any of the following things happened to you?": "You receive poorer service than other people at restaurants or stores," "People act as if they think you are not intelligent," "People act as if they are afraid of you," "People act as if they think you are dishonest," and "People act as if they are better than you." There were 5 categories of response for these items: "never" (coded 1), "a few times a year" (coded 2), "once a month" (coded 3), "once a week" (coded 4), and "almost every day" (coded 5). We refer to these as "everyday" experiences of racism. Although the latter questions did not refer specifically to "race" in asking about discrimination, research shows that most black Americans attribute experiences of discrimination to their race. ${ }^{24,57}$ Moreover, these questions were flanked by 2 other sets of questions that referred specifically to race.

Principal components factor analysis using an orthogonal rotation revealed 2 factor loadings, which confirmed the predetermined domains of the racism questions. ${ }^{17,50}$ The first factor, which included questions assessing "everyday" racism, had factor loadings ranging from 0.60 to 0.79 . The second factor, which included questions assessing "lifetime" experiences of unfair treatment, had loadings that ranged from 0.67 to 0.77 . The same 2 -factor solution resulted when we recoded the 5-level "everyday" racism variables into binary format ( $\geq 1$ month vs. $<1$ month) to agree with the scale used for the "lifetime" variables. The Cronbach- $\alpha$ for the 5 "everyday" racism items was 0.81 , indicating high internal consistency. In addition, we assessed the reproducibility over time of the racism questions among 1172 women who returned a duplicate questionnaire. Weighted $\kappa$-values indicated good reproducibility of responses (range 0.54-0.73), and the level of agreement did not vary by the length of the interval between the 2 questionnaires. 50

On the baseline survey, we collected data on a number of putative and established risk factors for uterine myomas, including age at menarche, oral contraceptive use, number of live births and still births (parity), age at each birth, height, current weight, alcohol intake, cigarette smoking, education, marital status, occupation, and recency of Papanicolaou test screening. On the 2003 questionnaire, we asked about household income and number of individuals supported by this income. Body mass index (BMI) was calculated as weight $(\mathrm{kg})$ divided by height squared (m2). A validation study of anthropometric measures among 115 study participants from the Washington, DC, area showed high correlation between self-reported and technician-measured weight $(r=0.97)$. Covariates that changed over time (eg, BMI, parity) were updated on follow-up questionnaires.

In analyses that assessed possible mechanisms by which racism affects myoma risk, we used data on the following measures of perceived or real life stressors: working on a second job (collected in 1995); working on a night shift (2005); exposure to violence victimization across the lifespan (2005); and psychologic distress, as measured by "depression treated with medication" $(1997,1999,2001,2003$, and 2005) and the CES-D depressive symptom scale (1999 and 2005). ${ }^{58}$ We also examined data on potential mediators of stress, such as hours per week of vigorous exercise (1997), levels of religiosity (2005), and coping (2005). In a validation study, vigorous exercise reported via self-administered questionnaire was correlated with measures by actigraph and 7-day diary. ${ }^{59}$ Religiosity was assessed using 3 questions adapted from the General Social Survey 60 : "How often do you usually attend religious services?," "To what extent is your religion or spirituality involved in understanding or dealing with stressful situations?," and "To what extent do you consider yourself a religious or spiritual 
person?" To measure coping, participants completed an abbreviated (9-item) scale based on an instrument developed by Carver ${ }^{61}$ designed to assess active coping, use of emotional support, use of instrumental support, positive reframing, and acceptance. Higher scores on the coping scale indicated higher coping skills. Because many of these measures were first assessed in 2005, 2 years after the end of the incident period for the present analysis (1997-2003), we considered these analyses exploratory.

\section{Assessment of Outcome}

On the 1999, 2001, and 2003 follow-up questionnaires, women were asked whether they had been diagnosed with "uterine fibroids" in the previous 2-year interval, and, if so, the calendar year in which they were first diagnosed and whether their diagnosis was confirmed by "pelvic examination" or "ultrasound/hysterectomy." In 2003, we changed "hysterectomy" to "surgery (eg, hysterectomy)" to capture women who may have had other surgical procedures, and we divided "ultrasound" and "surgery" into 2 separate questions. Cases were considered to be "surgically confirmed" if they reported confirmation by "surgery" in 2003 or if they reported both a diagnosis confirmed by "ultrasound/hysterectomy" and "hysterectomy" under a separate question in 1999 or 2001.

Ultrasound, the clinical standard used to confirm diagnoses, ${ }^{3}$ has high sensitivity (99\%) and specificity (91\%) relative to histologic evidence. 62,63 Our outcome definition includes cases confirmed by ultrasound or surgery because histologically confirmed cases represent only $10-30 \%$ of cases for whom ultrasound evidence is available, and because an analysis of risk factors for such cases may spuriously identify risk factors associated with tumor size, symptoms, or treatment preference. ${ }^{64}$ The Nurses' Health Study, a US prospective cohort study with methodology similar to our study, uses the same case definition. ${ }^{7}$ Diagnoses confirmed by pelvic examination only $(n=654)$ were treated as "noncases" because they could represent other gynecologic pathology 65 and our goal was to maximize the specificity of outcome classification. 66

We assessed the accuracy of self-reported diagnosis in a random sample of 248 cases confirmed by ultrasound or surgery. Cases were mailed supplemental surveys regarding their initial date of diagnosis, method of confirmation, symptoms, and treatment. We also asked for permission to review their medical records. We obtained medical records from 127 of the 128 women who gave permission and confirmed the self-report by medical record in $122(96 \%)$. Among the $188(76 \%)$ cases who completed the supplemental survey, $71 \%$ reported myoma-related symptoms before being diagnosed with the condition, with menorrhagia (53\%) and pelvic pain (46\%) being the most common. Over $87 \%$ of cases reported that their condition came to clinical attention because they sought treatment for symptoms or because a tumor was palpable at the time of a routine pelvic examination. There were no important differences between cases who did and did not release their medical records with respect to established risk factors for myomas, 67 suggesting that those who released their medical records were representative of the larger case group.

\section{Restriction Criteria}

Follow-up for the incidence of myomas began in March 1997 (the start of the second questionnaire cycle) because self-reported method of confirmation was first elicited on the 1999 questionnaire. We restricted the sample to premenopausal women with intact uteri because myomas are rare after menopause. ${ }^{3}$ Of the 53,176 women who completed the 1997 questionnaire, we excluded women with natural menopause $(n=5193)$, hysterectomy without removal of both ovaries $(n=6685)$, bilateral oophorectomy with or without hysterectomy ( $n$ $=4259)$, medication-induced menopause $(n=42)$, or unknown menopausal status $(n=418)$ at the start of follow-up (1997). We also excluded women who reported a myoma diagnosis before 
$1997(n=10,502)$, who reported myomas without information on year of diagnosis $(n=94)$ or method of confirmation $(\mathrm{n}=182)$, who did not complete a follow-up questionnaire $(\mathrm{n}=$ $1610)$, or who had missing data on key covariates $(n=2189)$, leaving a final sample of 22,002 women who were followed from 1997 through 2003. Women who were lost to follow-up or who had incomplete data on covariates had lower educational attainment than respondents, but were similar with respect to age, parity, age at menarche, and other determinants of myoma risk.

\section{Data Analysis}

Incident cases were defined as women who reported a first diagnosis of myomas confirmed by ultrasound or surgery. Person-years at risk were calculated from the start of follow-up (March 1997) until the myoma diagnosis, menopause, death, loss to follow-up, or the end of followup (March 2003), whichever came first. Cox regression models, stratified by age and time period, were used to estimate incidence rate ratios (IRRs) and 95\% confidence intervals (CIs) for the associations of interest. All analyses were carried out using SAS statistical software (version 9.1) (SAS Institute, Cary, NC).

Self-reported racism variables were analyzed individually. We also created 2 summary variables for each set of questions: the first was the average of response values from 5-level "everyday" racism items (range: 1-5), categorized into quartiles; the second was a count of the number of positive responses to the "lifetime" racism items (range: 0-3).

Multivariable models controlled for known or suspected risk factors for myomas. $66 \mathrm{We}$ constructed 2 sets of multivariable models: a model that controlled for age (1-year intervals) and calendar year (1997-1999, 1999-2001, 2001-2003), and a model that additionally controlled for reproductive and hormonal factors, including age at menarche (years), parity (births), age at first birth (years), years since last birth $(<5,10-14,15-19, \geq 20)$, and oral contraceptive use (current, past, never), as well as lifestyle and socioeconomic factors: BMI $\left(<20,20-24,25-29,30-34, \geq 35 \mathrm{~kg} / \mathrm{m}^{2}\right)$, cigarette smoking (current, past, never), current alcohol use ( $<1,1-6, \geq 7$ drinks/wk), education ( $\leq 12,13-15,16, \geq 17$ years), marital status (married or living with partner, divorced/separated/widowed, single), occupation (white collar, nonwhite collar, unemployed, unknown/missing), income ( $\leq \$ 25,000, \$ 25,001-50,000$,

$\$ 50,001-100,000,>\$ 100,000$, missing), geographic region (South, Northeast, Midwest, and West), and nativity status (foreign-born, US-born). Adjustment for age resulted in a 5\% and $7 \%$ change in the summary IRRs for "everyday" and "lifetime" racism, respectively.

Adjustment for other individual covariates had smaller effects on the IRRs. Tests for trend were calculated by including in the regression model a single ordinal variable coded as the score of each exposure category. 68

To examine whether the association between perceived racism and myomas was modified by education, income, or other factors by which study participants might differ from the general population of US black women, we conducted likelihood ratio tests that compared models with and without cross-product terms between the summary racism variables and selected covariates. In addition, we assessed effect modification by nativity status, coping, and other factors that have been shown to modify the relation between racism and health outcomes. $50-55$ Departures from the proportional hazards assumption were tested by the likelihood ratio test comparing models with and without cross-product terms between the summary racism variables and time-dependent age ( $<35$ vs. $\geq 35$ years).

\section{RESULTS}

Frequency distributions of the self-reported racism questions from the 1997 survey are shown in Table 1. The percent of study participants who reported racism in their "everyday" lives 
ranged from 55\% ("afraid of you") to 90\% ("better than you"). The percent who reported "lifetime" experiences of racism ranged from $24 \%$ ("by police") to 55\% ("on the job").

Selected characteristics of the sample according to summary measures of "everyday" and "lifetime" racism are shown in Table 2. Everyday experiences of racism were inversely related to age, being married or partnered, living in the Northeast, being foreign-born, and having a recent Papanicolaou test, and positively related to BMI, smoking, alcohol use, and living in the Midwest. Lifetime experiences of racism were inversely related to living in the South and being foreign-born, and positively related to age, working in a white-collar occupation, smoking, alcohol use, and living in the West or Midwest. Relative to native-born women, foreign-born women were younger, more educated, had higher incomes and higher coping scores, and were more likely to have older ages at menarche, lower BMI, and live in the Northeast (data not shown). In both groups, $90 \%$ reported having had a Papanicolaou test in the prior 2 years.

During 107,127 person-years of follow-up, 3440 incident cases of uterine myomas confirmed by ultrasound $(n=2774)$ or surgery $(n=666)$ were reported. The IRRs for all 5 measures of "everyday" racism were above 1.0, although the associations were weak and often nonlinear (Table 3). IRRs increased monotonically with increasing scores of the "everyday" racism summary variable $(P$-trend $<0.001)$.

Job, housing, and police discrimination were each weakly positively associated with myoma risk (Table 4). The IRRs increased monotonically with increasing number of "lifetime" events reported $(P$-trend $<0.001)$.

Foreign-born women ( $\mathrm{n}=1295 ; 6 \%$ of sample) had a higher incidence of myomas than nativeborn women (multivariable IRR $=1.20 ; 95 \% \mathrm{CI}=1.05-1.38)^{69}$ but consistently reported lower levels of racism than native-born women (data not shown). Positive associations between selfreported racism and risk of myomas were found among native-born women, whereas null associations were found among foreign-born women (Table 5). The largest difference between native-born and foreign-born women was observed for the "lifetime" summary variable $(P$ interaction $=0.008$ ).

Overall results did not vary according to case definition (ultrasound vs. surgery), age, questionnaire cycle, education, income, or Papanicolaou test screening, which we used as a proxy for gynecologic surveillance (data not shown). Results were unchanged when we included myomas confirmed by pelvic examination $(n=654)$ as cases. We did not find any evidence that other potential markers of stress in our study - eg, violence victimization, nightshift work, caregiving responsibilities —-were independently associated with myoma risk, with the exception of depression and depressive symptoms (data not shown), even though all of these measures were associated with perceived racism. Moreover, control for these other potential markers of stress had little effect on the positive associations between perceived racism and myomas. With respect to the potential stress mediators (exercise, religiosity, and coping skills), none was independently associated with myoma risk. However, the association between "everyday" racism and myoma was weaker among women who scored above the median on the abbreviated Carver coping scale relative to below the median (Table 6). The results for "lifetime" racism did not vary substantially by coping levels. A similar phenomenon was observed for vigorous exercise (data not shown), such that among women who exercised vigorously for $\geq 2$ hours per week, the "everyday" racism-myoma association was weaker compared with those exercising $<2$ hours per week $(P$-interaction $=0.09)$, but the associations with "lifetime" racism did not vary $(P=0.78)$. Religiosity did not modify the association between racism and myomas. 


\section{DISCUSSION}

In the present study, self-reported experiences of racism were associated with an increased risk of uterine myomas. Associations did not vary according to case definition (ie, confirmation by ultrasound vs. surgery), age, education, income, or levels of gynecologic screening, but the associations were notably weaker among foreign-born women and among women with higher coping skills ("everyday" racism only).

The negative impact of racism on health-related behaviors ${ }^{20}$ could increase myoma risk via heavy alcohol consumption, poor diet, and overweight or obesity. ${ }^{70-72}$ However, we found that the association between racism and myomas persisted after adjustment for various healthseeking and health-related behaviors (eg, Papanicolaou test screening, alcohol consumption, and BMI), suggesting that other mechanisms are at play. Other potential markers of "stress" (lifetime violence victimization, working on a second job, childcare or caregiving responsibilities, night shift work, and physician diagnosed depression) were positively associated with perceived racism but not with myoma risk. Moreover, control for these measures had little impact on the strength of the association between racism and myoma. These findings suggest that stressors other than racism do not explain the observed association and that the type of stress induced by racism may be different from other types of stress.

The association between "everyday" racism and myomas was weaker among women with high coping skills as measured by the Carver coping scale, ${ }^{61}$ but the association with "lifetime" racism was similar in both coping groups. A similar interaction was observed for vigorous exercise. The observation that coping skills and exercise modified the effect of racism supports a stress mechanism. These findings agree with studies showing that allostatic load can be mediated or "buffered" by social support ${ }^{73-75}$ and exercise. ${ }^{76}$ Our findings also suggest that stress mediators have a larger impact on chronic than acute exposure to racism, as the buffering effects were most pronounced for the "everyday" racism associations. However, because coping was measured after the occurrence of myoma, a cautious interpretation of these findings is warranted.

Foreign-born women reported lower levels of perceived racism than native-born women, consistent with findings from several studies of US immigrants. $77-80$ According to Waters, voluntary immigrants to the United States tend to "see prejudice and discrimination as more isolated occurrences, and as temporary barriers to be overcome, rather than as permanent, pervasive symptoms of a society that has overarching enmity toward them.,77(p. 147) Immigrants may downplay race in their perceptions of interpersonal relations, thereby making them less likely to define discriminatory events as racism. If foreign-born women who experience unfair treatment are less likely to perceive it as race-based, this might explain the lack of association between racism and myoma risk in this subgroup.

Another explanation for the absence of an effect among foreign-born blacks is that they are more likely to challenge unjust or unequal treatment 77 and have more resources for buffering the effects of discrimination. $51-53,55,81$ In a study of more than 4000 women and men, those who were conscious of instances of discrimination and who challenged discrimination (ie, tried to do something about unfair treatment and talked to others about it) had a lower risk of elevated blood pressure relative to those who were less aware of discriminatory acts and less likely to challenge them. ${ }^{82}$ If, as suggested by Waters, ${ }^{77}$ foreign-born women are more likely to challenge racism, and the act of challenging these events protects against myoma risk, we might also observe smaller effects in this subgroup. In agreement with prior data, foreign-born women had higher coping scores on average than native-born women in our study. Nonetheless, given the relatively small number of such women in this subgroup, we cannot rule out chance as a possible explanation. 
Measures of self-reported racism in the present study have been widely used $17,50,83$ and demonstrate high reproducibility both within our cohort 50 and in other studies. ${ }^{17,24,83}$ Exploratory factor analysis confirmed the preconceptualized domains of "everyday" and "lifetime" experiences of racism, suggesting that these questions are capturing the underlying constructs they were intended to measure. The prevalence of reported perceived discrimination is consistent with other studies that have measured perceived racism. ${ }^{17,82}$ Because the racism data were collected before the diagnosis of myoma, any error in the reporting of racism is unlikely to depend on the outcome and will generally result in bias towards the null.

A limitation of the present study is that myoma diagnoses were self-reported. However, in our validation study, ${ }^{67}$ the diagnosis was confirmed in more than $96 \%$ of the cases from whom we obtained medical records. There was little difference between the cases who did and did not release their medical records with respect to reported symptoms, method of diagnosis, or important risk factors for myomas. Not all study participants were screened for myomas and true cases may have missed, particularly those with asymptomatic disease. However, our data should more accurately represent women with symptomatic tumors because, a low percentage of cases (13\%) were detected incidentally and because rates of myoma diagnoses in our study are similar to rates reported in other US studies based on prospective cohort and hospital discharge data. ${ }^{67}$ Symptomatic myomas reflect the burden of disease in reproductive-aged women. 6

The association between perceived racism and myomas was evident after adjustment for several lifestyle and behavioral risk factors, as well as important measures of socioeconomic status (education, occupation, income, and marital status), although it is still possible that confounding by unmeasured or unknown risk factors contributed to the observed associations.

The Black Women's Health Study is a convenience sample of women with higher levels of education than the general population. Nonetheless, prevalence estimates of established risk factors for myomas - eg, age at menarche ${ }^{84}$ and parity 84 - are similar to those found in nationally representative studies. Because the association between perceived racism and myomas in US-born participants did not vary appreciably by other factors such as education, income, and age, we expect the positive findings to be generalizable to a broader population of US black women.

In summary, we found that self-reported experiences of racism were positively associated with risk of uterine myomas in US-born black women and that greater coping skills might buffer this association. Racial discrimination is a prevalent and pervasive problem in the United States, and self-reported racism has been linked to several mental and physical health outcomes. 20 Although the associations seen here are modest, the prevalence of perceived racism is high enough that a causal association could explain a non-negligible fraction of the excess disease burden of uterine myomas in black women.

\section{ACKNOWLEDGMENTS}

We acknowledge the ongoing contributions of Black Women's Health Study participants and staff.

Supported by National Cancer Institute Grant CA58420.

\section{REFERENCES}

1. Buttram VC, Reiter RC. Uterine leiomyomata: etiology, symptomatology, and management. Fertil Steril 1981;36:433-445. [PubMed: 7026295]

2. Coronado GD, Marshall LM, Schwartz SM. Complications in pregnancy, labor, and delivery with uterine leiomyomas: a population-based study. Obstet Gynecol 2000;95:764-769. [PubMed: 10775744] 
3. Stewart EA. Uterine fibroids. Lancet 2001;357:293-298. [PubMed: 11214143]

4. Wilcox LS, Koonin LM, Pokras R, et al. Hysterectomy in the United States, 1988-1990. Obstet Gynecol 1994;83:549-555. [PubMed: 8134065]

5. Farquhar CM, Steiner CA. Hysterectomy rates in the United States 1990-1997. Obstet Gynecol 2002;99:229-234. [PubMed: 11814502]

6. Flynn M, Jamison M, Datta S, et al. Health care resource use for uterine fibroid tumors in the United States. Am J Obstet Gynecol 2006;195:955-964. [PubMed: 16723104]

7. Marshall LM, Spiegelman D, Barbieri RL, et al. Variation in the incidence of uterine leiomyoma among premenopausal women by age and race. Obstet Gynecol 1997;90:967-973. [PubMed: 9397113]

8. Brett KM, Marsh JV, Madans JH. Epidemiology of hysterectomy in the United States: demographic and reproductive factors in a nationally representative sample. J Womens Health 1997;6:309-316. [PubMed: 9201665]

9. Baird DD, Dunson DB, Hill MC, et al. High cumulative incidence of uterine leiomyoma in black and white women: ultrasound evidence. Am J Obstet Gynecol 2003;188:100-107. [PubMed: 12548202]

10. Kjerulff KH, Langenberg P, Seidman JD, et al. Uterine leiomyomas: racial differences in severity, symptoms, and age at diagnosis. J Reprod Med 1996;41:483-490. [PubMed: 8829060]

11. Kjerulff KH, Guzinski GM, Langenberg PW, et al. Hysterectomy and race. Obstet Gynecol 1993;82:757-764. [PubMed: 8414322]

12. Kjerulff KH, Langenberg P, Guzinski GM. The socioeconomic correlates of hysterectomies in the United States. Am J Public Health 1993;83:106-108. [PubMed: 8417592]

13. Williams DR, Collins C. Racial residential segregation: a fundamental cause of racial disparities in health. Public Health Rep 2001;116:404-416. [PubMed: 12042604]

14. Van Houtven CH, Voils CI, Oddone EZ, et al. Perceived discrimination and reported delay of pharmacy prescriptions and medical tests. J Gen Intern Med 2005;20:578-583. [PubMed: 16050850]

15. Williams DR, Neighbors H. Racism, discrimination and hypertension: evidence and needed research. Ethn Dis 2001;11:800-816. [PubMed: 11763305]

16. Williams DR, Collins C. U.S. socioeconomic and racial differences in health: patterns and explanations. Annu Rev Sociol 1995;21:349-386.

17. Williams DR, Yu Y, Jackson JS, et al. Racial differences in physical and mental health. Socioeconomic status, stress and discrimination. J Health Psychol 1997;2:335.

18. Feagin, JR.; McKinney, KD. The Many Costs of Racism. Rowman \& Littlefield; Lanham, MD: 2003.

19. Krieger, N. Discrimination and health. In: Berkman, L.; Kawachi, I., editors. Social Epidemiology. Oxford University Press; Oxford: 2000. p. 36-75.

20. Paradies Y. A systematic review of empirical research on self-reported racism and health. Int J Epidemiol 2006;35:888-901. [PubMed: 16585055]

21. Rein MS, Nowak RA. Biology of uterine myomas and myometrium in vitro. Semin Reprod Endocrinol 1992;10:310-319.

22. Rein MS, Barbieri RL, Friedman AJ. Progesterone: a critical role in the pathogenesis of uterine myomas. Am J Obstet Gynecol 1995;172:14-18. [PubMed: 7847524]

23. Sozen I, Arici A. Cellular biology of myomas: interaction of sex steroids with cytokines and growth factors. Obstet Gynecol Clin North Am 2006;33:41-58. [PubMed: 16504805]

24. Krieger N, Smith K, Naishadham D, et al. Experiences of discrimination: validity and reliability of a self-report measure for population health research on racism and health. Soc Sci Med 2005;61:1576-1596. [PubMed: 16005789]

25. McEwen BS. Protective and damaging effects of stress mediators: allostasis and allostatic load. N Eng J Med 1998;338:171-179.

26. Seeman TE, Singer BH, Rowe JW, et al. Price of adaptation-allostatic load and its health consequences. MacArthur studies of successful aging. Arch Intern Med 1997;157:2259-2268. [PubMed: 9343003]

27. Geronimus AT, Hicken M, Keene D, et al. "Weathering" and age patterns of allostatic load scores among blacks and whites in the United States. Am J Public Health 2006;96:826-833. [PubMed: 16380565] 
28. McEwen BS, Seeman T. Protective and damaging effects of mediators of stress. Elaborating and testing the concepts of allostasis and allostatic load. Ann N Y Acad Sci 1999;896:30-47. [PubMed: 10681886]

29. Matyakhina L, Freedman RJ, Bourdeau I, et al. Hereditary leiomyomatosis associated with bilateral, massive, macronodular adrenocortical disease and atypical Cushing Syndrome: a clinical and molecular genetic investigation. J Clin Endocrinol Metab 2005;90:3773-3779. [PubMed: 15741255]

30. Bel'skaia GD. [The role of biogenic amines in the mechanism of uterine hemorrhage in uterine myoma]. Akush Ginekol (Mosk) Feb;1990:17-21.

31. Jung BH, Bai SW, Chung BC. Endogenous urinary steroids in premenopausal women with uterine leiomyomas. Int J Gynecol Obstet 2004;84:55-60.

32. Luoto R, Rutanen EM, Auvinen A. Fibroids and hypertension-a crosssectional study of women undergoing hysterectomy. J Reprod Med 2001;46:359-364. [PubMed: 11354837]

33. Boynton-Jarrett R, Rich-Edwards J, Malspeis S, et al. A prospective study of hypertension and risk of uterine leiomyomata. Am J Epidemiol 2005;161:628-638. [PubMed: 15781952]

34. Faerstein E, Szklo M, Rosenshein NB. Risk factors for uterine leiomyoma: a practice-based casecontrol study. II. Atherogenic risk factors and potential sources of uterine irritation. Am J Epidemiol 2001;153:11-19. [PubMed: 11159140]

35. Kam K, Park Y, Cheon M, et al. Effects of immobilization stress on estrogen-induced surges of luteinizing hormone and prolactin in ovariectomized rats. Endocrine 2000;12:279-287. [PubMed: 10963049]

36. Tilbrook AJ, Canny BJ, Serapiglia MD, et al. Suppression of the secretion of luteinizing hormone due to isolation/restraint stress in gonadectomised rams and ewes is influenced by sex steroids. $\mathbf{J}$ Endocrinol 1999;160:469-481. [PubMed: 10076193]

37. Breen KM, Billings HJ, Wagenmaker ER, et al. Endocrine basis for disruptive effects of cortisol on preovulatory events. Endocrinology 2005;146:2107-2115. [PubMed: 15625239]

38. Skarzynski D, Kotwica J. Mechanism of noradrenaline influence on the secretion of ovarian oxytocin and progesterone in conscious cattle. J Reprod Fertil 1993;97:419-424. [PubMed: 8388956]

39. Kotwica J, Bogack M, Rekawiecki R. Neural regulation of the bovine corpus luteum. Domest Anim Endocrinol 2002;23:299-308. [PubMed: 12142246]

40. Miszkiel G, Kotwica J. Mechanism of action of noradrenaline on secretion of progesterone and oxytocin by the bovine corpus luteum in vitro. Acta Vet Hung 2001;49:39-51. [PubMed: 11402689]

41. Bogacki M, Kotwica J. Influence of noradrenaline on progesterone synthesis and post-translational processing of oxytocin synthesis in the bovine corpus luteum. Theriogenology 1999;52:91-102. [PubMed: 10734408]

42. Lahoz MM, Nagle CA, Porta M, et al. Cortisol response and ovarian hormones in juvenile and cycling female Cebus monkeys: effect of stress and dexamethasone. Am J Primatol 2007;69:551-561. [PubMed: 17177312]

43. Papenfuss F, Bodis J, Tinneberg HR, et al. The modulatory effect of catecholamines on gonadotropinstimulated granulosa cell steroid secretion. Arch Gynecol Obstet 1993;253:97-102. [PubMed: 8215613]

44. Shi CZ, Zhuang LZ. Stimulatory effect of norepinephrine on progesterone production by human first trimester placenta explants in vitro. Life Sci 1993;52:1657-1665. [PubMed: 8387142]

45. Bodis J, Tinneberg HR, Papenfuss F, et al. Cholinergic stimulation of progesterone and estradiol secretion by human granulosa cells cultured in serum-free medium. Gynecol Endocrinol 1993;7:8387. [PubMed: 8213231]

46. Kornya L, Bodis J, Koppan M, et al. Modulatory effect of acetylcholine on gonadotropin-stimulated human granulosa cell steroid secretion. Gynecol Obstet Invest 2001;52:104-107. [PubMed: 11586037]

47. Sood AK, Bhatty R, Kamat AA, et al. Stress hormone-mediated invasion of ovarian cancer cells. Clin Cancer Res 2006;12:369-375. [PubMed: 16428474]

48. Lutgendorf SK, Cole S, Costanzo E, et al. Stress-related mediators stimulate vascular endothelial growth factor secretion by two ovarian cancer cell lines. Clin Cancer Res 2003;9:4514-4521. [PubMed: 14555525] 
49. Moss NS, Benditt EP. Human atherosclerotic plaque cells and leiomyoma cells. Comparison of in vitro growth characteristics. Am J Pathol 1975;78:175-190. [PubMed: 163592]

50. Cozier Y, Palmer JR, Horton NJ, et al. Racial discrimination and the incidence of hypertension in US black women. Ann Epidemiol 2006;16:681-687. [PubMed: 16458539]

51. Gee GC, Ryan A, Laflamme DJ, et al. Self-reported discrimination and mental health status among African descendants, Mexican Americans, and other Latinos in the New Hampshire REACH 2010 initiative: the added dimension of immigration. Am J Public Health 2006;96:1821-1828. [PubMed: 17008579]

52. Gee GC, Chen J, Spencer MS, et al. Social support as a buffer for perceived unfair treatment among Filipino Americans: differences between San Francisco and Honolulu. Am J Public Health 2006;96:677-684. [PubMed: 16507727]

53. Noh S, Beiser M, Kaspar V, et al. Perceived racial discrimination, depression, and coping: a study of Southeast Asian refugees in Canada. J Health Soc Behav 1999;40:193-207. [PubMed: 10513144]

54. Tull ES, Sheu YT, Butler C, et al. Relationships between perceived stress, coping behavior and cortisol secretion in women with high and low levels of internalized racism. J Natl Med Assoc 2005;97:206212. [PubMed: 15712783]

55. Noh S, Kaspar V. Perceived discrimination and depression: moderating effects of coping, acculturation, and ethnic support. Am J Public Health 2003;93:232-238. [PubMed: 12554575]

56. Rosenberg L, Adams-Campbell LL, Palmer JR. The Black Women's Health Study: a follow-up study for causes and preventions of illness. J Am Med Womens Assoc 1995;50:56-58. [PubMed: 7722208]

57. Kessler RC, Mickelson KD, Williams DR. The prevalence, distribution, and mental health correlates of perceived discrimination in the United States. J Health Soc Behav 1999;40:208-230. [PubMed: 10513145]

58. Radloff LS. The CES-D scale: a self-report depression scale for research in the general population. Appl Psychol Meas 1977;1:385-401.

59. Carter-Nolan PL, Adams-Campbell LL, Makambi K, et al. Validation of physical activity instruments: Black Women's Health Study. Ethn Dis 2006;16:943-947. [PubMed: 17061751]

60. Davis, JA.; Smith, TW. General Social Surveys, 1972-2004: Cumulative Codebook. University of Chicago, National Opinion Research Center; Chicago, IL: 2005.

61. Carver CS. You want to measure coping but your protocol's too long: consider the brief COPE. Int J Behav Med 1997;4:92-100. [PubMed: 16250744]

62. Loutradis D, Antsaklis A, Creatsas G, et al. The validity of gynecological ultrasonography. Gynecol Obstet Invest 1990;29:47-50. [PubMed: 2190879]

63. Dueholm M, Lundorf E, Hansen ES, et al. Accuracy of magnetic resonance imaging and transvaginal ultrasonography in the diagnosis, mapping, and measurement of uterine myomas. Am J Obstet Gynecol 2002;186:409-415. [PubMed: 11904599]

64. Schwartz, SM.; Marshall, LM. Uterine leiomyomata. In: Goldman, MB.; Hatch, MC., editors. Women and Health. Academic Press; San Diego, CA: 2000. p. 240-252.

65. Robboy, SJ.; Andersen, MC.; Russell, P. Pathology of the Female Reproductive Tract. Churchill Livingstone; London: 2002.

66. Rothman, KJ.; Greenland, S. Precision and validity in epidemiologic studies. In: Rothman, KJ.; Greenland, S., editors. Modern Epidemiology. 2nd ed.. Lippincott-Raven; Philadelphia, PA: 1998. p. 115-134.

67. Wise LA, Palmer JR, Stewart EA, et al. Age-specific incidence rates for self-reported uterine leiomyomata in the Black Women's Health Study. Obstet Gynecol 2005;105:563-568. [PubMed: 15738025]

68. Breslow, NE.; Day, NE. Statistical Methods in Cancer Research, Vol II: The Design and Analysis of Cohort Studies. IARC; Lyon, France: 1987.

69. Wise LA, Palmer JR, Rosenberg L, et al. Risk of uterine leiomyomata according to birthplace and geographic region in the Black Women's Health Study [Abstract]. Ann Epidemiol 2004;14:622.

70. Wise LA, Palmer JR, Harlow BL, et al. Risk of uterine leiomyomata in relation to tobacco, alcohol and caffeine consumption in the Black Women's Health Study. Hum Reprod 2004;19:1746-1754. [PubMed: 15218005] 
71. Wise LA, Palmer JR, Spiegelman D, et al. Influence of body size and body fat distribution on risk of uterine leiomyomata in U.S. black women. Epidemiology 2005;16:346-354. [PubMed: 15824551]

72. Marshall LM, Spiegelman D, Manson JE, et al. Risk of uterine leiomyomata among premenopausal women in relation to body size and cigarette smoking. Epidemiology 1998;9:511-517. [PubMed: 9730029]

73. Roy MP, Steptoe A, Kirschbaum C. Life events and social support as moderators of individual differences in cardiovascular and cortisol reactivity. J Pers Soc Psychol 1998;75:1273-1281. [PubMed: 9866187]

74. Singer B, Ryff CD. Hierarchies of life histories and associated health risks. Ann N Y Acad Sci 1999;896:96-115. [PubMed: 10681891]

75. Weinstein M, Goldman N, Hedley A, et al. Social linkages to biological markers of health among the elderly. J Biosoc Sci 2003;35:433-453. [PubMed: 12887222]

76. Tsatsoulis A, Fountoulakis S. The protective role of exercise on stress system dysregulation and comorbidities. Ann N Y Acad Sci 2006;1083:196-213. [PubMed: 17148741]

77. Waters, MC. Black Identities: West Indian Immigrant Dreams and American Realities. Russell Sage; New York: 1999.

78. Gee GC. A multilevel analysis of the relationship between institutional and individual racial discrimination and health status. Am J Public Health 2002;92:615-623. [PubMed: 11919062]

79. Landrine H, Klonoff EA. The schedule of racist events: a measure of racial discrimination and a study of its negative physical and mental health consequences. J Black Psychol 1996;22:144-168.

80. Gary LE. African-American men's perceptions of racial discrimination: a sociocultural analysis. Soc Work Res 1995;19:207-217.

81. Denner J, Kirby D, Coyle K, et al. The protective role of social capital and cultural norms in Latino communities: a study of adolescent births. Hisp J Behav Sci 2001;23:3-21.

82. Krieger N, Sidney S. Racial discrimination and blood pressure: the CARDIA Study of young black and white adults. Am J Public Health 1996;86:1370-1378. [PubMed: 8876504]

83. James K, Lovato C, Khoo G. Social identity correlates of minority workers' health. Acad Manage J 1994;37:383-396.

84. Abma JC, Chandra A, Mosher WD, et al. Fertility, family planning, and women's health: new data from the 1995 National Survey of Family Growth. Vital Health Stat 1997;23:19. 
TABLE 1

Prevalence of Self-Reported Racism in 22,002 Black Women's Health Study Participants (1997)

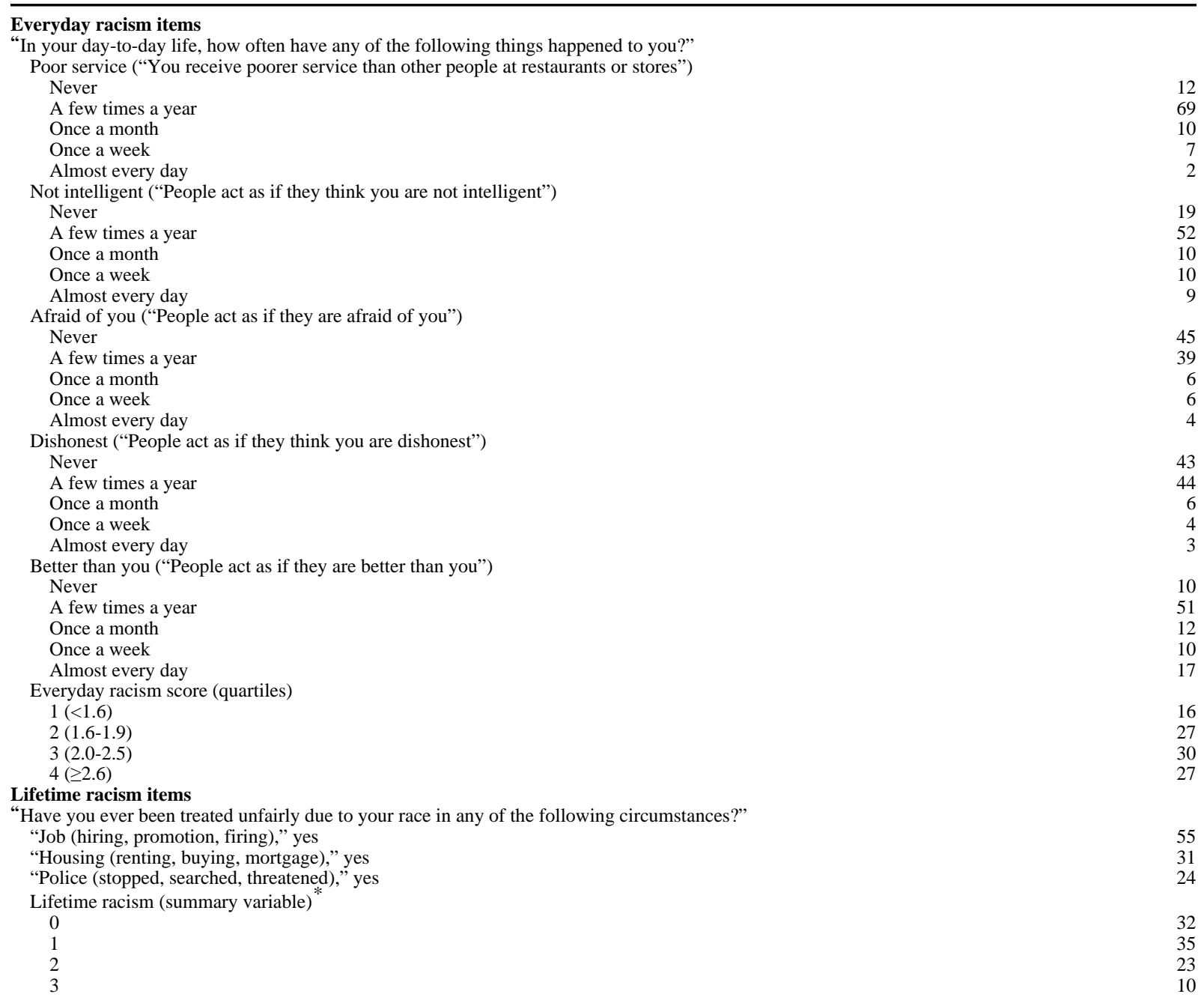

* Of the 3 lifetime racism items, no. for which woman answered affirmatively. 


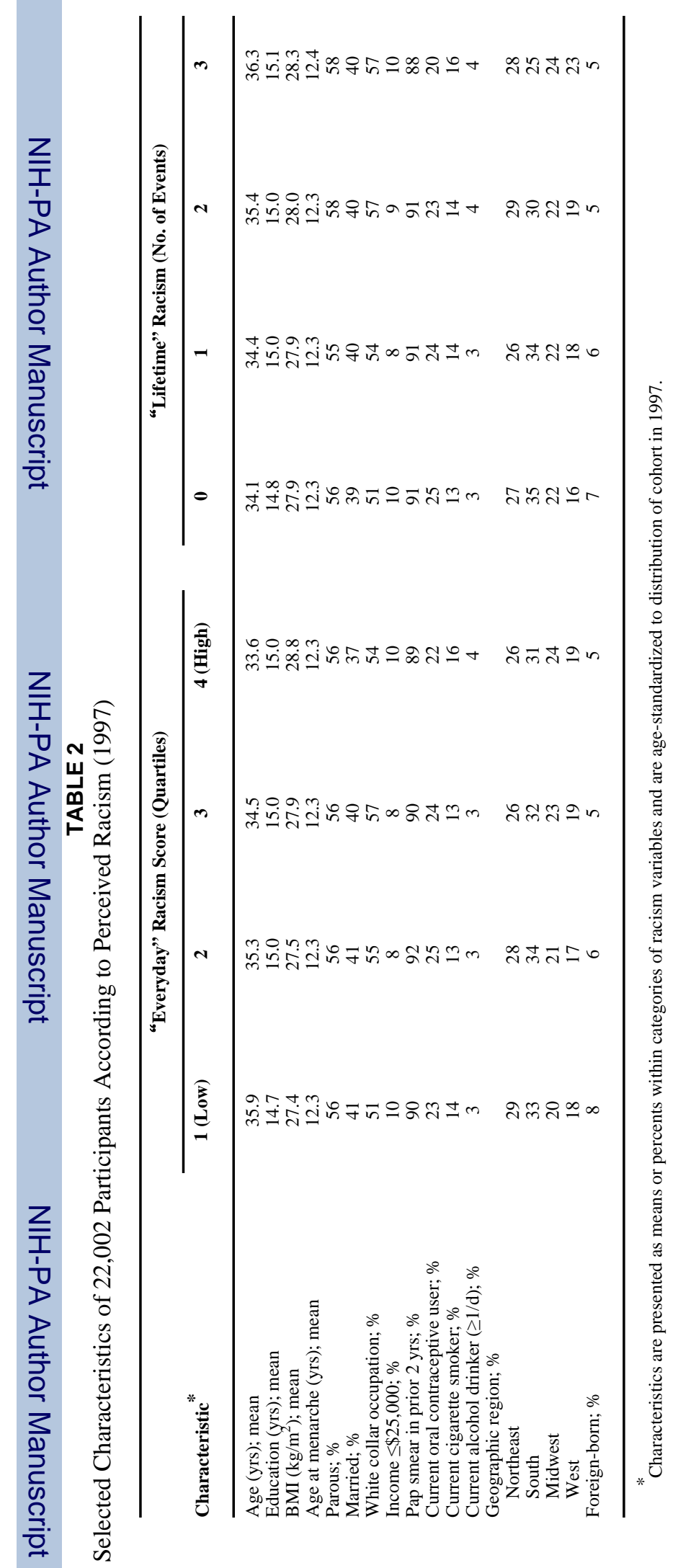

Epidemiology. Author manuscript; available in PMC 2007 December 20. 


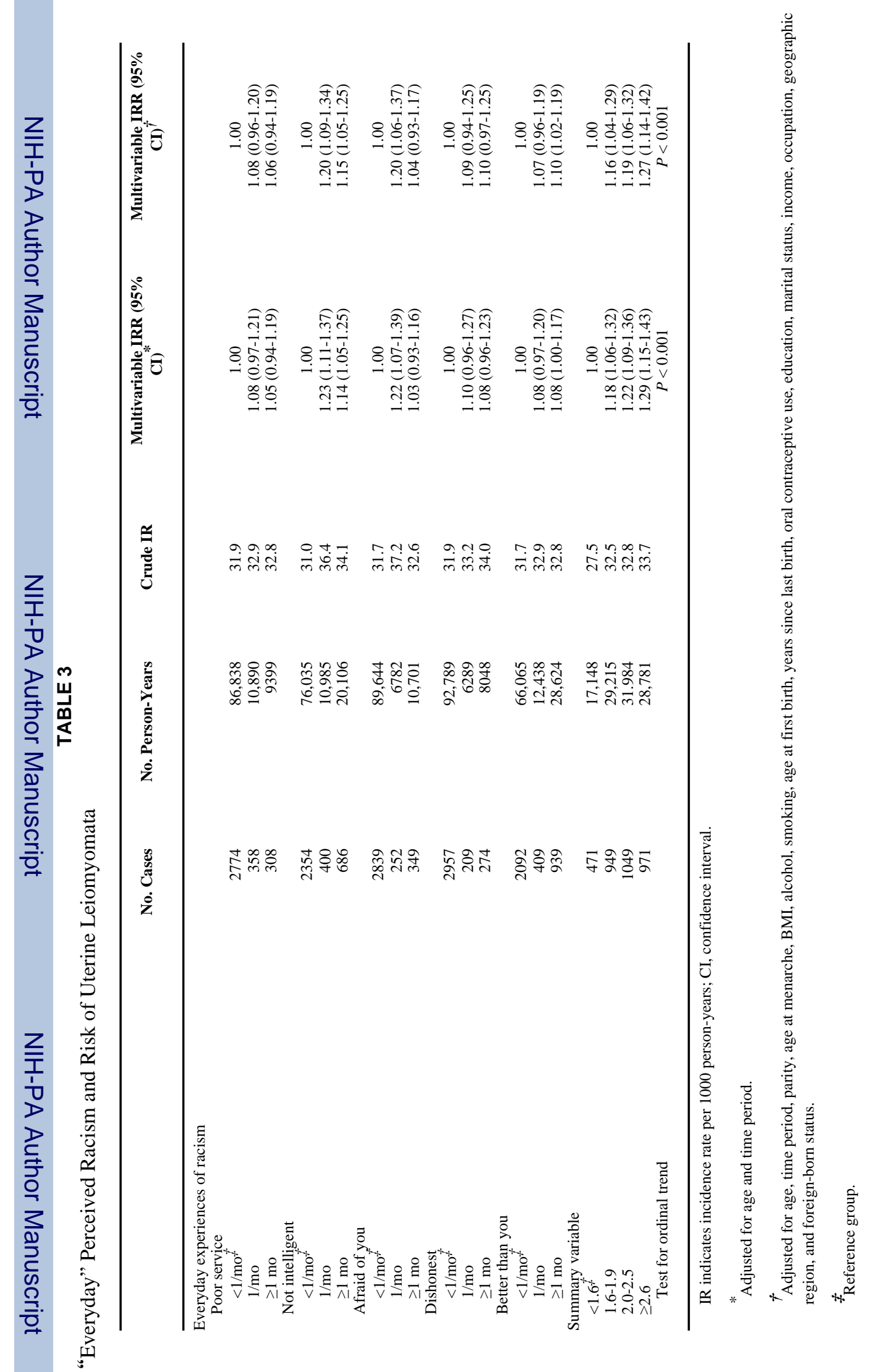

Epidemiology. Author manuscript; available in PMC 2007 December 20. 


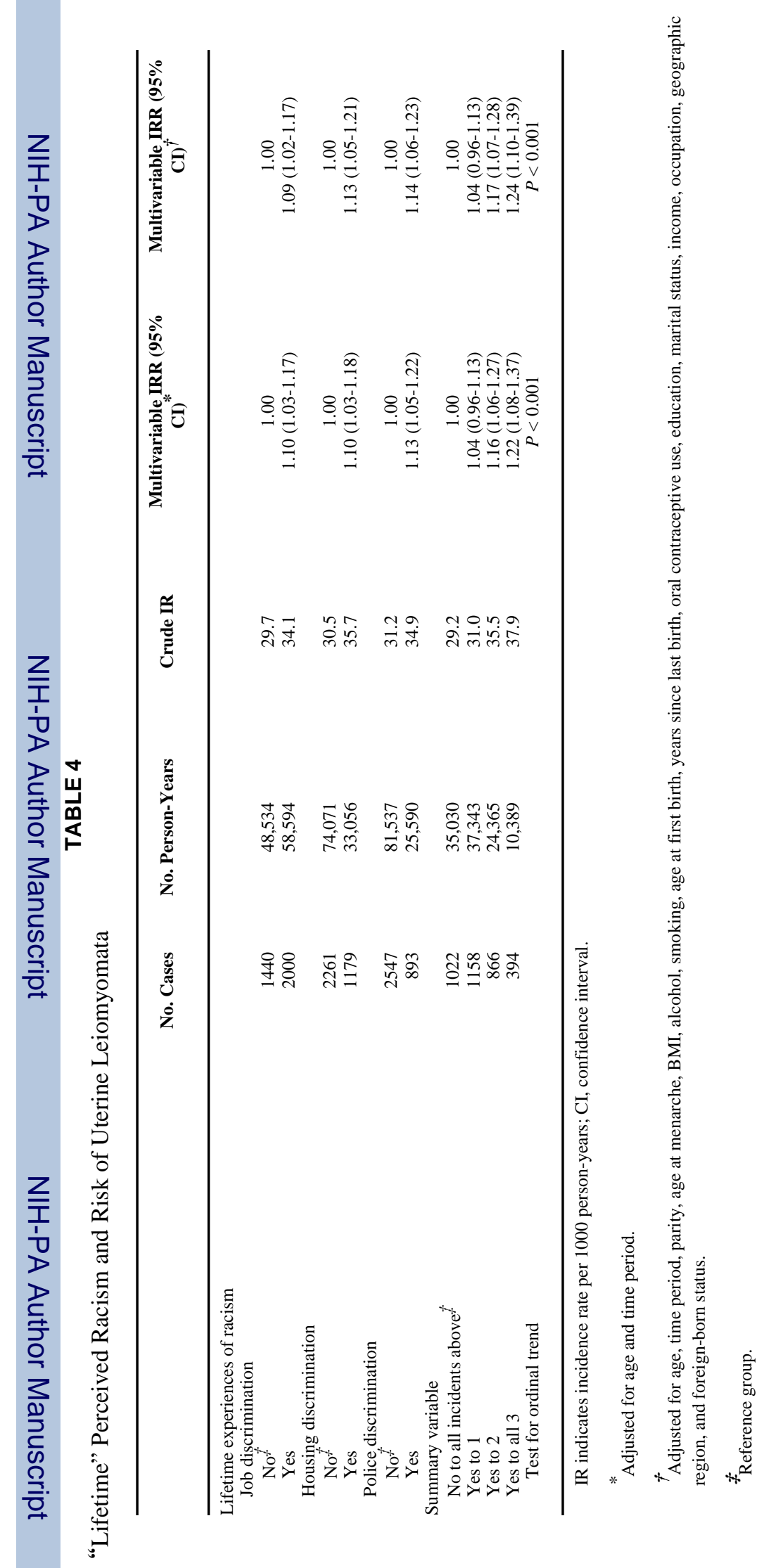

Epidemiology. Author manuscript; available in PMC 2007 December 20. 


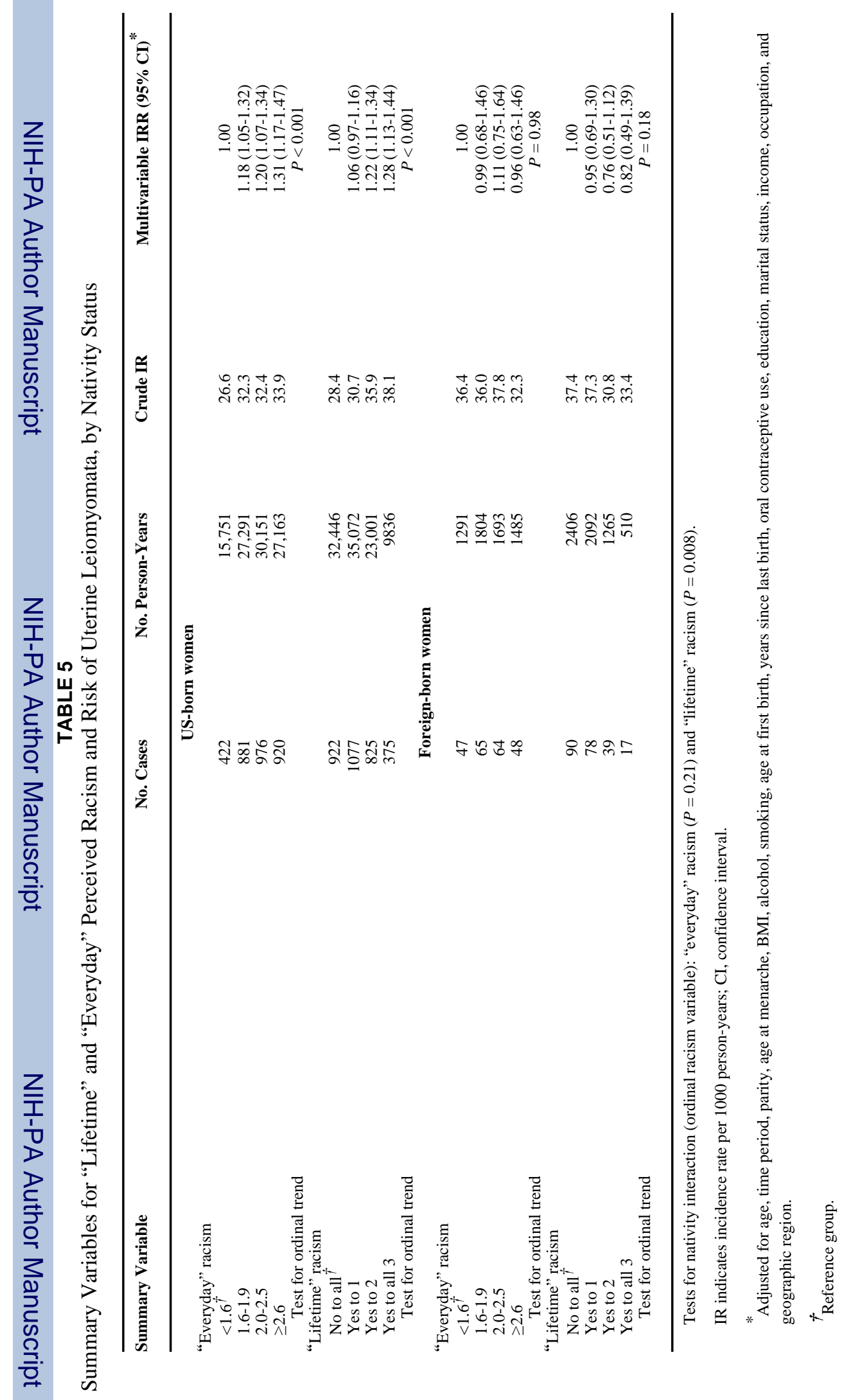


t]

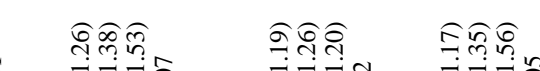

\&

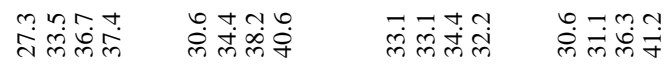

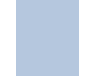

